\title{
Obtenção de concreto leve utilizando agregados reciclados
}

\author{
Obtaining lightweight concrete using recycled aggregates
}

\author{
Paulo César Correia Gomes \\ Tatiana Frassy Falcão de Alencar \\ Natália Vieira da Silva \\ Karoline Alves de Melo Moraes \\ Sérgio Cirelli Angulo
}

\section{Resumo}

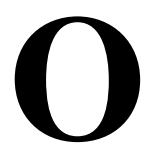

concreto leve pode ser obtido pela substituição do agregado convencional por agregado de menor densidade, como a argila expandida, a qual apresenta também alta porosidade e absorção de água elevada. Essas propriedades se assemelham às dos agregados reciclados de resíduos de construção, o que os torna aptos para a obtenção de um concreto leve. Porém, os agregados reciclados diferem quanto a composição variável, menor resistência a esforços e à abrasão, e formato mais irregular. Assim, $\mathrm{o}$ artigo analisa como algumas propriedades dos agregados reciclados influenciam no comportamento do concreto leve nos estados fresco e endurecido. O estudo utilizou dois tipos de agregados reciclados, um oriundo de blocos vazados de concreto com EPS (ARBCE) e outro de blocos cerâmicos (ARBC), com o propósito de entender a variabilidade dos materiais caracterizando as composições desses agregados e verificar a viabilidade de aplicação deles na obtenção de concretos leves. Os agregados reciclados foram britados por dois diferentes equipamentos (moinho argamassadeira para o ARBC e britador de martelo para o ARBCE). Os agregados reciclados obtidos desses processos distintos apresentaram distribuição granulométrica e forma diferentes. Com ambos os agregados reciclados foi possível produzir concretos leves, ou seja, com massa específica abaixo de 2,00 g/ $\mathrm{cm}^{3}$. As resistências à compressão aos 28 dias entre 9,0 e 13,0 $\mathrm{MPa}$ indicam uso em elementos sem função estrutural, mas aplicáveis em componentes construtivos de resistência moderada (p.ex. painéis e blocos).

Paulo César Correia Gomes Universidade Federal de Alagoas Maceió - AL - Brasil

Tatiana Frassy Falcão de

Alencar Companhia de Saneamento de Alagoas Maceió - AL - Brasil

Natália Vieira da Silva Universidade Federal de Alagoas Maceió - AL - Brasil

Karoline Alves de Melo Moraes Universidade Federal de Alagoas Maceió - AL - Brasil

Sérgio Cirelli Angulo Universidade de São Paulo São Paulo - SP - Brasil

Recebido em 15/08/14 Aceito em 18/04/15
Palavras-chaves: Concreto leve. Agregados reciclados. Propriedades.

\section{Abstract}

Lightweight concrete can be obtained by replacing conventional aggregates by a lower density aggregate, such as expanded clay, which also present high porosity and high water absorption. These properties resemble those of recycled aggregates from construction waste, contributing to the achievement of a lightweight concrete. However, recycled aggregates have characteristics that make them very different: variable composition, low resistance to abrasion, more irregular shapes. This article analyses some properties of recycled coarse aggregates and their influence on the behaviour of lightweight concrete in fresh and hardened state. The study used two types of recycled coarse aggregates, one originating from concrete blocks with EPS (ARBCE) and another one from ceramic blocks $(A R B C)$, with the purpose of understanding the variability of the materials characterising the composition of these aggregates in order to verify the feasibility of application of these aggregates in lightweight concrete. The aggregates were crushed by two different equipments (mortar mixer mill and hammer mill). The recycled aggregates obtained through these different crushing processes presented different size distribution and shapes. In spite of that, it was possible to produce the two recycled lightweight concretes using both aggregate types. The compressive strength at 28 days was between 9.0 and $13.0 \mathrm{MPa}$, pointing to their use in elements without any structural function, but applicable in building components of moderate strength (e.g. panels and blocks).

Keywords: Lightweight concrete. Recycled aggregates. Properties. 


\section{Introdução}

Normalmente, a designação de concreto leve é utilizada para identificar concretos com estrutura porosa, geralmente à base de ligantes hidráulicos, com massa específica inferior à dos concretos tradicionais (ROSSIGNOLO, 2003). De acordo com a NBR 12655 (ABNT, 2006a), o concreto leve é definido como o concreto endurecido que, quando seco em estufa, apresenta massa específica entre 0,8 e 2,0 g/ $\mathrm{cm}^{3}$. Segundo Maycá, Cremonini e Recena (2008), concretos leves podem ser obtidos por intrusão de ar no estado fresco, tanto pela incorporação direta na massa de aditivos químicos tensoativos quanto pela eliminação dos finos ou teores reduzidos de pasta de cimento capazes de prover vazios na estrutura granular dos agregados. Os concretos leves são então classificados em concreto com agregados leves, concreto celular e concreto sem finos (ROSSIGNOLO; AGNESINI, 2005) (Figura 1).

Dependendo do tipo de agregado, traço e dosagem da mistura, concretos produzidos com agregados leves podem atingir resistências moderadas e altas. Maycá, Cremonini e Recena (2008) relatam que existem diversos agregados leves que podem ser utilizados em substituição total ou parcial aos agregados convencionais, como argila expandida, pumicita (pedra-pomes), vermiculita e cinza volante sintetizada. Segundo a NBR NM 35 (ABNT, 1995), os agregados leves não devem possuir massa unitária no estado seco e solto acima de $1,12 \mathrm{~g} / \mathrm{cm}^{3}$ para os agregados miúdos e de 0,88 $\mathrm{g} / \mathrm{cm}^{3}$ para os agregados graúdos. A NBR 12655 (ABNT, 2006a) estabelece que os agregados leves devem apresentar massa específica igual ou menor que $1,80 \mathrm{~g} / \mathrm{cm}^{3}$.

O agregado leve sintético poliestireno expandido (EPS), conhecido popularmente como isopor, com massa específica inferior a $0,030 \mathrm{~g} / \mathrm{cm}^{3}$, tem sido também utilizado para produzir concretos com massa específica entre $600 \mathrm{~g} / \mathrm{cm}^{3}$ e $1.800 \mathrm{~g} / \mathrm{cm}^{3}$, e resistências à compressão entre $4 \mathrm{MPa}$ e $12 \mathrm{MPa}$, dependendo do tamanho e da quantidade de EPS (GANESH BABU; SARADHI BADU, 2002; MILED et al., 2004). Segundo Ganesh Babu e Saradhi Badu (2002), agregados não absorventes e hidrofóbicos como os grânulos de EPS não sofrem absorção de água, prejudicando a produção de concreto leve. Ainda conforme os autores, a utilização de EPS não só reduz o peso do concreto mas também possibilita também a redução da permeabilidade e aumenta a resistência aos ataques químicos, devido a sua natureza inerte e célula fechada. Investigações feitas na zona de contato do concreto com os grânulos de EPS mostraram que o contato entre esses dois materiais é muito próximo, sem fratura ou microfissuras, e a adesão dos dois componentes depende do tamanho e da forma dos grânulos de EPS usados (LAUKAITIS; ZURAUSKAS; KERIEN, 2003).

Vários estudos têm analisado a influência da argila expandida na obtenção de concreto leve (GIACOMIN, 2005; MACHADO JÚNIOR; AGNESINI, 1999; MAYCÁ; CREMONINI; RECENA, 2008; MORAVIA et al., 2006; ROSSIGNOLO, 2009). A porosidade e a elevada absorção de água das argilas expandidas afetam significativamente a trabalhabilidade, a zona de transição (pasta-agregado) e a resistência do concreto. A quantidade de água absorvida pelos agregados leves e a velocidade com que ela é absorvida dependem da porosidade total, conectividade entre os poros e umidade do agregado antes da mistura. Para agregados leves com valores elevados de absorção de água é recomendado realizar uma pré-umidificação, para evitar prejuízo na trabalhabilidade do concreto fresco (MORAVIA et al., 2006; LO; GAO; JEARY, 1998; ROSSIGNOLO, 2003). Entretanto, Rossignolo (2009) verificou que a zona de transição dos concretos com argila expandida apresentava espessura, porosidade e teor de hidróxido de cálcio menores se comparados aos concretos com agregados convencionais, devido à absorção de água dos agregados leves e à redução da relação água/cimento da pasta.

Os agregados reciclados também apresentam porosidade elevada e menor densidade, assim como a argila expandida. Porém, os agregados reciclados são mais heterogêneos (o que dificulta a uniformidade de suas propriedades) e menos resistentes. Além disso, esses agregados possuem teores de finos e/ou materiais pulverulentos mais elevados, e formato mais irregular ou textura superficial mais rugosa (LEITE, 2001; CARRIJO, 2005; TENÓRIO, 2007). Para Angulo (2000), as fases tendem a ser mais porosas na seguinte ordem: rochas, concretos/argamassas e cerâmicas. Dessa forma, é de se esperar que, quanto maior for a quantidade de fases mais porosas, como a cerâmica, maior será a absorção do agregado reciclado. 
Figura 1 - Tipos de concreto leve: (a) concreto com agregados leves, (b) concreto celular e (c) concreto sem finos
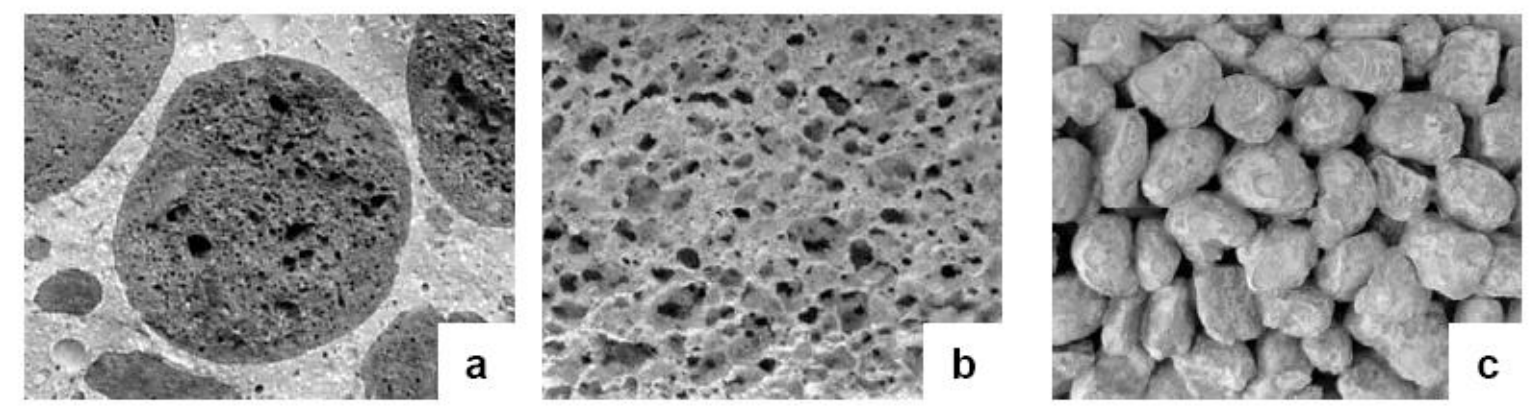

Fonte: Rossignolo e Agnesini (2005).

Assim como ocorre com os agregados leves, a absorção dos agregados reciclados influencia diretamente nas propriedades dos concretos. Diversos estudos (OLIVEIRA; VAZQUEZ, 1996; ANGULO, 2000; LEITE, 2001; POON et al., 2004; TENÓRIO, 2007; RODRIGUES, 2011) afirmam que os agregados reciclados utilizados na condição seca absorvem uma parte considerável da água da mistura, podendo influenciar negativamente na trabalhabilidade. Para isso a prémolhagem dos agregados reciclados antes da mistura também tem sido recomendada (LEITE, 2001).

Leite (2001) propõe a determinação da curva de absorção de água dos agregados reciclados no tempo. Os valores de absorção nos primeiros 10 min de imersão encontrados por Leite (2001), Carrijo (2005) e Tenório (2007) correspondem a $50 \%, 70 \%$ a $86 \%$ e $90 \%$ da absorção de água respectivamente. Segundo Tenório (2007), a diferença entre os valores encontrados leva a crer que essa propriedade depende de cada agregado reciclado (ou seja, da distribuição e do tamanho dos poros de cada material). Como constatado pelo autor e em muitos casos citados na literatura, 10 min é o tempo a partir do qual a absorção começa a se processar de forma mais lenta.

Alguns autores têm definido como procedimento de pré-saturação dos agregados reciclados o tempo de $10 \mathrm{~min}$ de pré-molhagem e a quantidade de água de $50 \%$ da água de absorção, alegando que após 10 min a taxa de absorção é reduzida. Isso evita que haja redução significativa da relação a/c efetiva das misturas e também que os agregados liberem água para o concreto e, consequentemente, reduzam a resistência mecânica deste (LEITE, 2001; CARRIJO, 2005; FERREIRA; BRITO; BARRA, 2011). Tenório (2007) e Silva (2011) adotaram como dosagem da água de absorção na mistura o valor de $70 \%$ da absorção total, que correspondia ao tempo de 1 min de imersão. Esse tempo foi usado para o tempo de pré-molhagem do agregado reciclado com água de absorção já como parte do processo de mistura.

Ferreira, Brito e Barra (2011), comparando concretos com agregado reciclado e realizando a produção com pré-molhagem e com compensação de água da mistura, concluíram que ambos os métodos de produção interferem pouco na resistência à compressão e evitam que a absorção de água do agregado reciclado afete a consistência do concreto. O método de compensação de água da mistura tem a vantagem de tornar possível a produção de concreto com agregado reciclado de maneira semelhante à do concreto convencional.

Dentro desse contexto, o trabalho analisou a influência de agregados graúdos reciclados de diferentes origens e obtido de diferentes processos de cominuição na obtenção de concretos leves. Para isso foram utilizados dois tipos de agregados reciclados, oriundos de diferentes resíduos, um com predominância de blocos cerâmicos (ARBC), e o outro, de blocos de concreto com EPS (ARBCE), sendo processados com diferentes equipamentos. As características físicas (granulometria, forma, massa específica e absorção) dos agregados reciclados foram determinadas, e em seguida avaliada e verificada a influência dessas características na dosagem, produção, trabalhabilidade e massa específica do concreto leve. Os concretos leves obtidos para cada tipo de agregado reciclado foram moldados em corpos de prova cilíndricos, e as propriedades de massa específica e resistência à compressão foram analisadas.

\section{Materiais e métodos}

Os materiais utilizados no estudo foram cimento Portland CP-II-F 32 (classificado de acordo com a norma NBR 11578 (ABNT, 1991)), areia natural quartzosa (módulo de finura de 3,14 e massa específica de $2,6 \mathrm{~g} / \mathrm{cm}^{3}$ ) e agregados reciclados graúdos (com dimensão maior que 4,8 mm). 


\section{Agregados reciclados graúdos}

\section{Origem}

Os agregados reciclados foram oriundos de resíduos de blocos obtidos em canteiros de obras de construção de edifícios para moradia de diferentes construtoras da cidade de Maceió. As construtoras eram parceiras dos projetos de inovação tecnológica financiados pela Finep, pelo CNPq e pela Capes. Numa obra os resíduos foram gerados na execução das alvenarias com blocos cerâmicos (quebra de blocos e das aberturas na alvenaria para passagem de tubulações elétricas e hidráulicas) e continham argamassa de assentamento, chapisco e predominância de pedaços de blocos cerâmicos em forma de placa, sendo denominados no estudo de agregados reciclados de bloco cerâmico (ARBC). Na outra obra os resíduos foram gerados na execução da alvenaria dos blocos vazados de concreto contendo poliestireno expandido (EPS, sigla em inglês), originados da produção, pois a fábrica estava instalada no próprio local da obra, e da quebra de blocos durante a confecção de alvenarias para divisão dos pavimentos, sendo denominados no estudo de agregados reciclados de bloco vazado de concreto com EPS (ARBCE).

\section{Beneficiamento}

Após o armazenamento dos resíduos, o ARBC permanecia na obra para ser processado, já que a construtora possuía o equipamento de cominuição aplicado para esse resíduo, e o ARBCE era transportado para o Laboratório de Estruturas e Materiais (Lema) da Universidade Federal de Alagoas (Ufal), onde se encontrava o outro equipamento utilizado no estudo para cominuição desse resíduo. A rota do processo de cominuição do ARBC foi através do moinho argamassadeira (Figura 2a), baseado no mecanismo de atrito entre as partículas. O equipamento era da própria obra e utilizado para produção de agregados reciclados miúdos destinados à produção de argamassas aplicadas em ambientes internos (GOMES et al., 2010, 2011), porém, dependendo do tempo de moagem, observava-se a geração de uma quantidade considerável de agregados graúdos, os quais foram utilizados neste estudo. Para o ARBCE, a rota foi através de um moinho de martelos (Figura 2b), o qual, mediante mecanismo de impacto, gera agregados com menos finos, se comparado ao moinho argamassadeira.
Em ambas as rotas os agregados reciclados foram peneirados em peneiras com malha de abertura 25 $\mathrm{mm}$ passante e de $4,75 \mathrm{~mm}$ retido, a fim de se obterem os agregados graúdos reciclados de acordo com a especificação da NBR 7211 (ABNT, 2009). Na Figura 3 a o ARBC caracteriza uma composição de agregados graúdos reciclados praticamente de blocos de cerâmica vermelha. $\mathrm{Na}$ Figura $3 b$ o ARBCE apresenta predominância de material cimentício (pasta de cimento e rocha), incluindo EPS.

Os agregados reciclados foram caracterizados com relação às propriedades de granulometria, forma, massa unitária, massa específica e absorção de água:

(a) granulometria: as distribuições granulométricas dos agregados graúdos reciclados foram realizadas de acordo com a norma NBR NM 248 (ABNT, 2003a); e

(b) forma: pela Figura 3, a partir de uma análise visual preliminar, observa-se que o ARBC apresenta grãos com formato tendendo para lamelar, lamelaridade já observada no resíduo, diferentemente do ARBCE, que apresenta grãos mais cúbicos e de formato próximo ao dos agregados naturais. Devido à importância da avaliação da forma dos grãos, algumas técnicas foram aplicadas objetivando uma determinação mais precisa. Para isso foram utilizados três métodos de ensaios: NBR 7809 (ABNT, 2008a), NBR 5564 (ABNT, 2011) e análise de imagem dinâmica (HAWLITSCHECK et al., 2013).

A partir da NBR 7809 (ABNT, 2008a) foi realizado o ensaio de índice de forma para as partículas com dimensão máxima característica maior que $9,5 \mathrm{~mm}$ por medida direta com paquímetro. As dimensões (comprimento e espessura) de 200 grãos entre $9,5 \mathrm{~mm}$ e $19,1 \mathrm{~mm}$ foram determinadas, sendo o número de grãos de cada fração retida calculado de acordo com as porcentagens de massa retida nas peneiras. O índice de forma (comprimento/espessura) de cada grão foi calculado, e a média deve ser inferior a 3,0, de acordo com o estabelecido pela NBR 7211 (ABNT, 2009).

A NBR 5564 (ABNT, 2011) determina a forma dos grãos por paquímetro e classifica-a em cúbica, alongada ou alongada lamelar (Figura 4), em função da razão entre a espessura e a largura (C/B) e da razão entre a largura e o comprimento (B/A). Este ensaio foi realizado a partir dos 200 grãos selecionados do ensaio anterior, apesar de esta norma exigir apenas 100 grãos para análise. 
Figura 2 - Detalhes dos equipamentos utilizados nas rotas de cominuição dos resíduos: (a) moinho argamassadeira (moagem) e (b) moinho martelo (impacto)
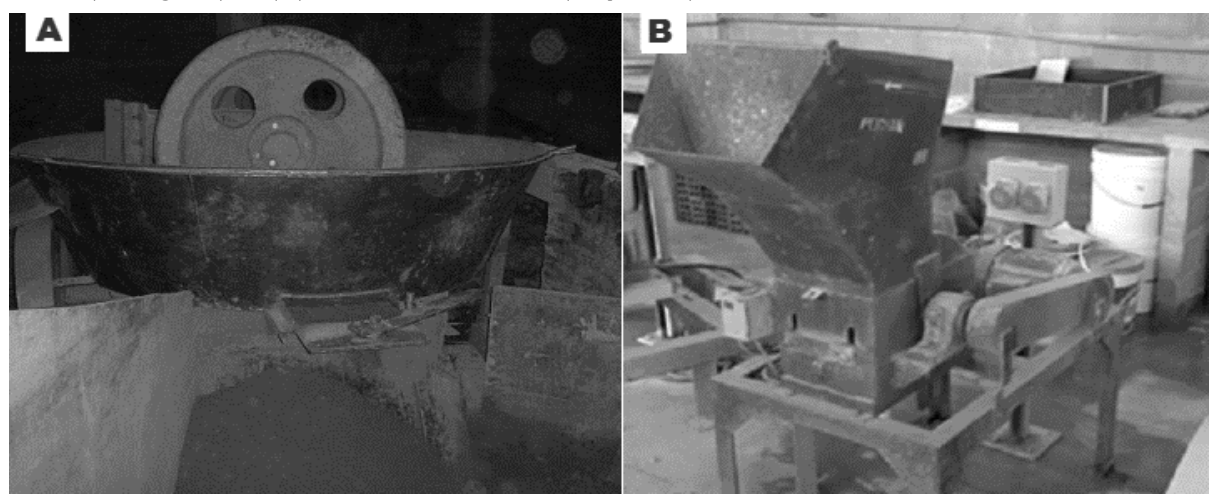

Figura 3 - Aspectos dos agregados reciclados graúdos após o peneiramento: (a) ARBC e (b) ARBCE
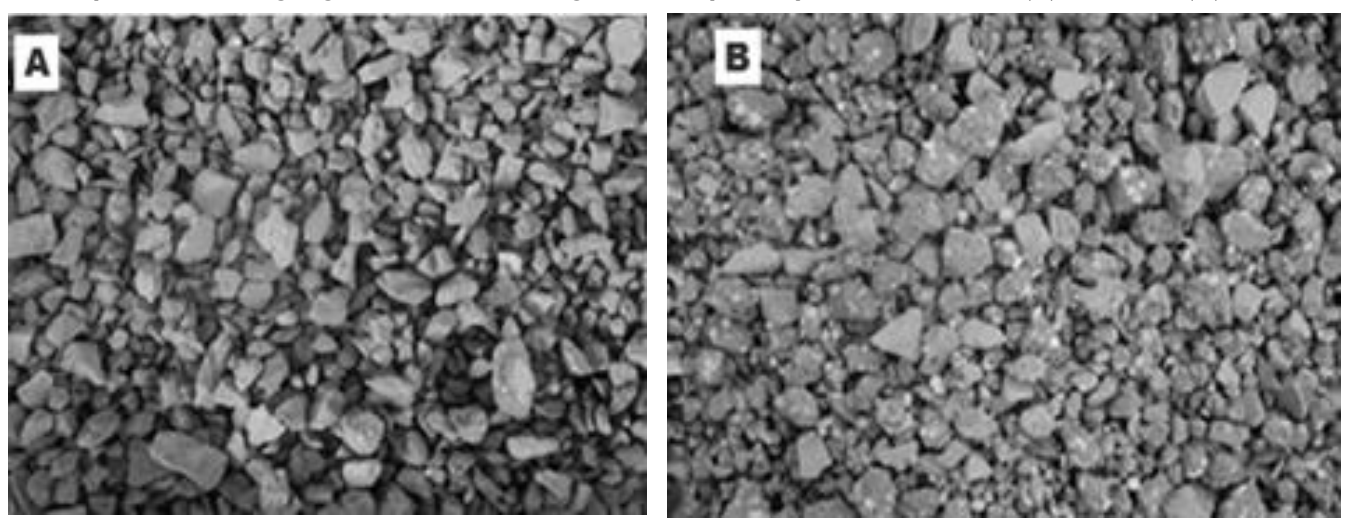

Figura 4 - Representação dos parâmetros de forma estabelecidos pela NBR 5564 (ABNT, 2011)

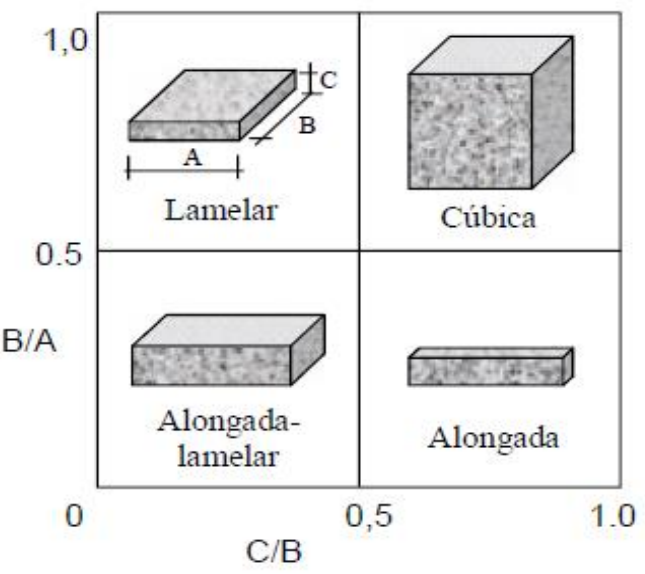

Fonte: Farias e Palmeira (2010).

A análise de imagem dinâmica empregou uma quantidade de amostra maior $(3 \mathrm{~kg}$ ) do que os demais ensaios normalizados e foi realizada no equipamento Camsizer, da marca Retsch (HAWLITSCHECK et al., 2013). As partículas caem por gravidade, de forma aleatória, num duto que contém duas câmaras (uma para partículas grandes e outra para partículas pequenas, contendo zoom), que registram cerca de 60 imagens/segundo, viáveis de ser iluminadas, ante o curto tempo de exposição, apenas por luz LED (90 $\mathrm{Hz}$ ), o que permite a análise de milhares de partículas em poucos minutos, aumentando significativamente a representatividade das partículas. As imagens obtidas foram processadas por análise de imagem, o que permitiu quantificar por meio da relação de aspecto (b/l - relação entre comprimento e largura dos grãos). 
$\mathrm{O}$ ensaio de massa unitária foi realizado a partir dos procedimentos da NBR NM 45 (ABNT, 2006b), e os ensaios de massa específica e absorção de água foram realizados de acordo com a norma NBR NM 53 (ABNT, 2003c).

\section{Dosagem dos concretos}

$\mathrm{O}$ concreto produzido teve a dosagem baseada em estudos prévios (TENÓRIO, 2007) em que se conseguiu produzir concretos com agregados reciclados e naturais, com massa específica reduzida. Essa dosagem de referência foi alterada de modo a se ajustar aos diferentes materiais deste estudo e visando à obtenção de um concreto com massa específica ainda mais reduzida (próximo de $2.000 \mathrm{~kg} / \mathrm{m}^{3}$ ), se enquadrando conforme a NBR 12655 (ABNT, 2006a) como concreto leve. Assim, optou-se por utilizar um elevado volume de agregado graúdo reciclado nas misturas, uma vez que estes possuem menor massa específica em relação ao agregado natural (areia natural). As quantidades dos materiais foram sendo ajustadas em volume para se atingir a massa específica desejada, obtendo-se as dosagens das misturas com ARBC e ARBCE em massa, que estão apresentadas na Tabela 1, onde os concretos foram chamados de CARBC e CARBCE respectivamente.

Verifica-se na Tabela 1 que, devido à menor massa específica do ARBCE, a dosagem desse é menor que a do ARBC, elevando consequentemente o teor de argamassa. O procedimento de produção dos concretos é esquematizado na Figura 5. Os concretos foram produzidos em betoneira. A quantidade da água de absorção e o tempo de mistura (Figura 5) foi de acordo com Tenório (2007) e Silva (2011).

O concreto inicialmente produzido foi o CARBC. Na Figura 6 é mostrado o aspecto visual dele. Verificou-se que a mistura apresentava um teor de argamassa insuficiente para envolver o ARBC, cujas partículas apresentavam formas lamelares.

Tabela 1 - Composição dos concretos com agregados reciclados graúdos ARBC e ARBCE

\begin{tabular}{|c|c|c|c|c|c|c|c|c|c|}
\hline \multirow[t]{2}{*}{ Dosagem } & \multirow{2}{*}{$\begin{array}{c}\text { Relação } \\
\text { a/c }\end{array}$} & \multicolumn{3}{|c|}{ Traço unitário } & \multicolumn{4}{|c|}{ Composição em massa $\left(\mathrm{kg} / \mathrm{m}^{3}\right)$} & \multirow{2}{*}{$\begin{array}{c}\text { Teor de } \\
\text { argamassa } \\
\text { seca } \\
\end{array}$} \\
\hline & & Cimento & $\begin{array}{l}\text { Agreg } \\
\text { miúdo } \\
\end{array}$ & $\begin{array}{l}\text { Agreg } \\
\text { graúdo }\end{array}$ & Água & Cimento & $\begin{array}{l}\text { Agreg. } \\
\text { miúdo }\end{array}$ & $\begin{array}{l}\text { Agreg. } \\
\text { graúdo }\end{array}$ & \\
\hline CARBC & 0,65 & 1 & 1,68 & 3,16 & 200 & 310 & 520 & 980 & 0,46 \\
\hline CARBCE & 0,65 & 1 & 1,68 & 2,77 & 200 & 310 & 520 & 860 & 0,49 \\
\hline
\end{tabular}

Figura 5 - Procedimento de mistura

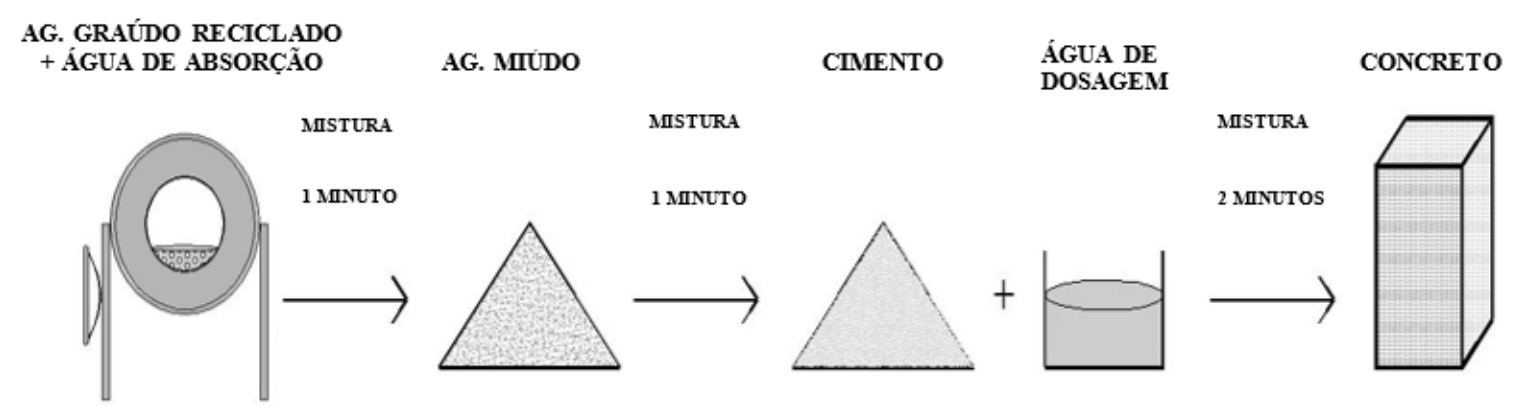

Figura 6 - Aspecto visual da mistura produzida com ARBC

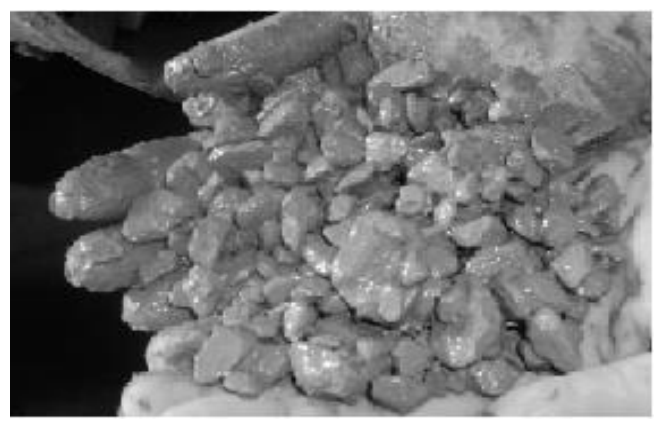

36 Gomes, P. C. C.; Alencar, T. F. F. de; Silva, N. V. da; Moraes, K. A. de M.; Angulo, S. C. 
Os concretos foram então ajustados e formulados para a mesma relação a/c, mesmo consumo de cimento e mesmo volume de agregados naturais e reciclados (Tabela 2). As principais mudanças foram aumentar o teor de argamassa, elevando a dosagem da areia natural e diminuindo a dosagem do agregado graúdo reciclado, e limitar o diâmetro das partículas em até $19 \mathrm{~mm}$, para tentar eliminar ao máximo os agregados maiores. Com relação ao teor de argamassa, segundo alguns estudos (GIACOMIN, 2005; ROSSIGNOLO, 2003; GONZÁLEZ; SANTOS, 2012), em virtude da menor massa específica dos agregados, os concretos leves apresentam teor de argamassa superior ao das misturas de concretos convencionais, o que também garante adequada trabalhabilidade.

As propriedades analisadas no estado fresco dos concretos foram: consistência pelo abatimento do tronco de cone, de acordo com a NBR NM 67 (ABNT, 1998); e determinação da massa específica e do teor de ar pelo método gravimétrico, conforme os procedimentos da NBR 9833 (ABNT, 2008b). Para a análise das propriedades no estado endurecido foram confeccionados três corpos de prova cilíndricos de $100 \mathrm{~mm}$ x $200 \mathrm{~mm}$ para cada concreto, seguindo as recomendações da NBR 5738 (ABNT, 2003b). A resistência à compressão foi determinada na idade de 28 dias, de acordo com o especificado na NBR
5739 (ABNT, 2007), e a massa específica, pela relação entre a massa do material seco e o volume total da amostra.

\section{Resultados e análises}

\section{Agregados reciclados graúdos}

\section{Granulometria}

$\mathrm{Na}$ Figura 7 estão comparadas as curvas granulométricas dos agregados reciclados com os limites das zonas granulométricas estabelecidas pela NBR NM 248 (ABNT, 2003a). Os agregados graúdos reciclados $\mathrm{ARBC}$ se enquadram no limite superior da zona 4,75/12,5 da norma, e os ARBCE não se encaixam em nenhuma das zonas granulométricas especificadas na norma, configurando uma deficiência na graduação de seus grãos para atendimento às normas vigentes de agregados naturais. Ambos os agregados apresentaram dimensão máxima característica igual a $19 \mathrm{~mm}$, porém os agregados ARBC possuem granulometria mais fina.

\section{Forma}

$\mathrm{Na}$ Tabela 3 estão apresentados os resultados obtidos para a análise de forma dos agregados por meio da NBR 7809 (ABNT, 2008a) e da NBR 5564 (ABNT, 2011), e a variação dos resultados analisados.

Tabela 2 - Composição dos concretos após ajuste da dosagem

\begin{tabular}{|c|c|c|c|c|c|c|c|c|c|}
\hline \multirow[b]{2}{*}{ Dosagem } & \multirow{2}{*}{$\begin{array}{c}\text { Relação } \\
\text { a/c }\end{array}$} & \multicolumn{3}{|c|}{ Traço unitário } & \multicolumn{4}{|c|}{ Materiais em massa $\left(\mathrm{kg} / \mathrm{m}^{3}\right)$} & \multirow{2}{*}{$\begin{array}{c}\text { Teor de } \\
\text { argamassa } \\
\text { seca }\end{array}$} \\
\hline & & Cimento & $\begin{array}{l}\text { Agreg. } \\
\text { miúdo }\end{array}$ & $\begin{array}{l}\text { Agreg. } \\
\text { graúdo }\end{array}$ & Água & Cimento & $\begin{array}{l}\text { Agreg. } \\
\text { miúdo }\end{array}$ & $\begin{array}{l}\text { Agreg. } \\
\text { graúdo }\end{array}$ & \\
\hline CARBC & 0,65 & 1 & 2,52 & 2,53 & 200 & 310 & 780 & 784 & 0,58 \\
\hline CARBCE & 0,65 & 1 & 2,52 & 2,23 & 200 & 310 & 780 & 688 & 0,61 \\
\hline
\end{tabular}

Figura 7 - Curvas granulométricas dos agregados graúdos reciclados ARBC e ARBCE, e limites da NBR NM 248 (ABNT, 2003)

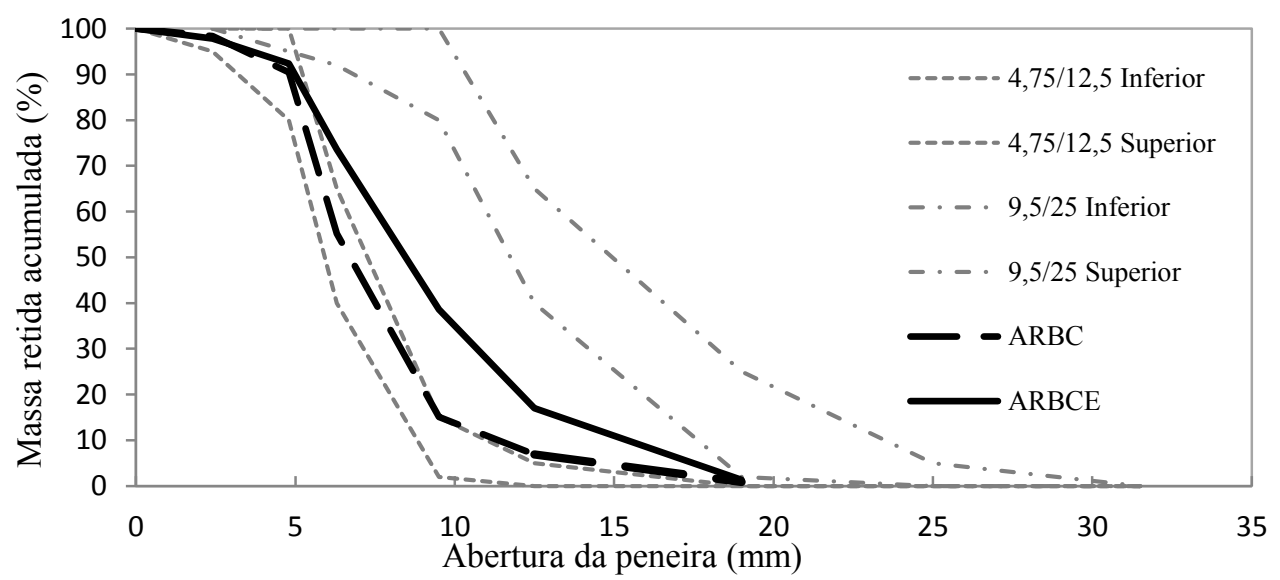


Tabela 3 - Determinação dos parâmetros de forma pela NBR 7809 (ABNT, 2008a) e pela NBR 5564 (ABNT, 2011)

\begin{tabular}{c|c|c|c|c|c|c|c}
\hline & \multicolumn{3}{c|}{ ARBC } & \multicolumn{3}{c}{ ARBCE } \\
\hline \multicolumn{2}{c}{ Peneira (mm) } & $\mathbf{9 , 5}$ & $\mathbf{1 2 , 5}$ & $\begin{array}{c}\text { MÉDIA } \\
\text { TOTAL }\end{array}$ & $\mathbf{9 , 5}$ & $\mathbf{1 2 , 5}$ & $\begin{array}{c}\text { MÉDIA } \\
\text { TOTAL }\end{array}$ \\
\hline \multirow{2}{*}{$\begin{array}{c}\text { Espessura } \\
\text { Largura }\end{array}$} & MÉDIA & 0,2 & 0,3 & 0,2 & 0,5 & 0,5 & 0,5 \\
\cline { 2 - 8 } Largura & $\begin{array}{c}\text { DESV. } \\
\text { PADRÃO }\end{array}$ & 0,1 & 0,1 & 0,1 & 0,1 & 0,1 & 0,1 \\
\hline \multirow{2}{*}{\begin{tabular}{c} 
Comprimento \\
\cline { 2 - 8 }
\end{tabular}} & MÉDIA & 1,1 & 0,7 & 0,9 & 0,8 & 0,8 & 0,8 \\
\cline { 2 - 8 } & $\begin{array}{c}\text { DESV. } \\
\text { PADRÃO }\end{array}$ & 0,4 & 0,2 & 0,3 & 0,1 & 0,1 & 0,1 \\
\hline \multirow{2}{*}{ Índice de forma } & MÉDIA & 4,7 & 5,8 & 5,2 & 3,0 & 3,0 & 3,0 \\
\cline { 2 - 8 } & $\begin{array}{c}\text { DESV. } \\
\text { PADRÃO }\end{array}$ & 2,0 & 3,0 & 2,5 & 1,1 & 1,0 & 1,0 \\
\hline
\end{tabular}

Os resultados mostram que o ARBCE atende no limite ao índice especificado na NBR 7809 (ABNT, 2008a); já o ARBC apresentou um índice bem superior ao da norma. No entanto, apesar da indicação de um índice, a norma não especifica quanto à forma predominante do agregado.

Analisando-se a partir das relações de forma apresentadas na NBR 5564 (ABNT, 2011), os agregados reciclados ARBC estudados apresentaram valores que os classificam na forma lamelar, já o ARBCE teve valores próximos de um agregado cúbico. Os motivos que levaram o ARBC a apresentar forma mais lamelar do que o ARBCE podem estar relacionados ao tipo de material (predominância de cerâmica vermelha) e ao equipamento utilizado para cominuição (moinho de argamassadeira).

$\mathrm{Na}$ Figura 8 apresentam-se as porcentagens dos grãos classificados de acordo com a NBR 5564 (ABNT, 2011). Grãos lamelares são de maior predominância no ARBC e no ARBCE, apesar de que este também apresentou uma porcentagem considerável de grãos cúbicos. Nas duas faixas granulométricas observadas $(9,5 \mathrm{~mm}$ e $12,5 \mathrm{~mm})$ dos dois agregados reciclados há predominância de grãos lamelares, apesar de serem materiais diferentes e seguirem rotas de cominuição distintas.

Na Figura 9 apresenta-se um comparativo entre os resultados obtidos pelo ensaio da norma NBR 7809 (ABNT, 2008a) e os obtidos por análise de imagem dinâmica. Há discrepância entre os resultados. O Camsizer (equipamento por análise de imagem dinâmica) verifica a relação b/l de todas as frações, enquanto a norma limita a análise para frações acima de $9,5 \mathrm{~mm}$. Com o aumento da representatividade (número de grãos caracterizados), percebe-se que o método da norma superestima a relação de aspecto.
Conforme observado anteriormente, o ARBC apresentou relação de aspecto superior ao ARBCE. Isso indica que, dentro das condições estudadas, a influência da origem do resíduo na forma do agregado foi mais significativa. O mecanismo de britagem do moinho argamassadeira, baseado no atrito entre grãos, não foi suficiente para alterar significativamente o formato dos grãos.

\section{Massa unitária, massa específica e absorção de água}

Os resultados dos ensaios de massa unitária, massa específica seca e absorção de água dos agregados reciclados estão apresentados na Tabela 4. A massa unitária do ARBCE foi inferior ao especificado $\left(0,88 \mathrm{~g} / \mathrm{cm}^{3}\right)$ pela NBR NM 35 (ABNT, 1995), sendo possível classificar esse agregado reciclado como agregado leve. Já a massa unitária do ARBC ficou ligeiramente acima do valor especificado, mas é cerca de $40 \%$ inferior à dos agregados naturais (entre 1,50 e 1,70 g/ $\mathrm{cm}^{3}$ ). As massas específicas dos agregados reciclados (ARBC e ARBCE) apresentaram-se aproximadamente $27,4 \%$ e $36,3 \%$ menores do que as dos agregados naturais $\left(2,7 \mathrm{~g} / \mathrm{cm}^{3}\right)$ respectivamente. A presença de EPS no ARBCE também contribuiu para esse menor valor. A absorção do ARBC foi superior em relação ao ARBCE, apesar de este apresentar visualmente maior porosidade. Os valores de absorção recomendados pela NBR 15116 (ABNT, 2004) para agregados reciclados graúdos $-\leq 7 \%$ para agregados com no mínimo $90 \%$ em massa de fragmentos à base de cimento Portland e rochas, e $\leq 12 \%$ para agregados mistos com menos de $90 \%-$ são inferiores aos obtidos pelo ARBCE e ARBC. Porém, verifica-se que a norma é direcionada para uso de agregados reciclados em concretos convencionais. Apesar de especificar que é sem função estrutural, não trata de agregados reciclados

38 Gomes, P. C. C.; Alencar, T. F. F. de; Silva, N. V. da; Moraes, K. A. de M.; Angulo, S. C. 
para concreto leve, o que mostra que o uso de agregados reciclados mais porosos e consequentemente mais leves com a finalidade de diminuir sua massa específica e de proporcionar menor massa ao concreto não é contemplado nessa norma.

Na Figura 10 é apresentada a curva que descreve o comportamento de absorção de cada agregado reciclado, usado para definir o tempo de prémolhagem e a percentagem de água de absorção usada na mistura, sendo apresentados os dados obtidos a partir da média de duas determinações. $\mathrm{O}$ tempo de 1 min de submersão corresponde a $70 \%$ e $95 \%$ do valor da absorção de água medido em 24 $\mathrm{h}$ para o ARBC e o ARBCE respectivamente.

Figura 8 - Distribuição da forma dos grãos (em \%) nas faixas granulométricas analisadas

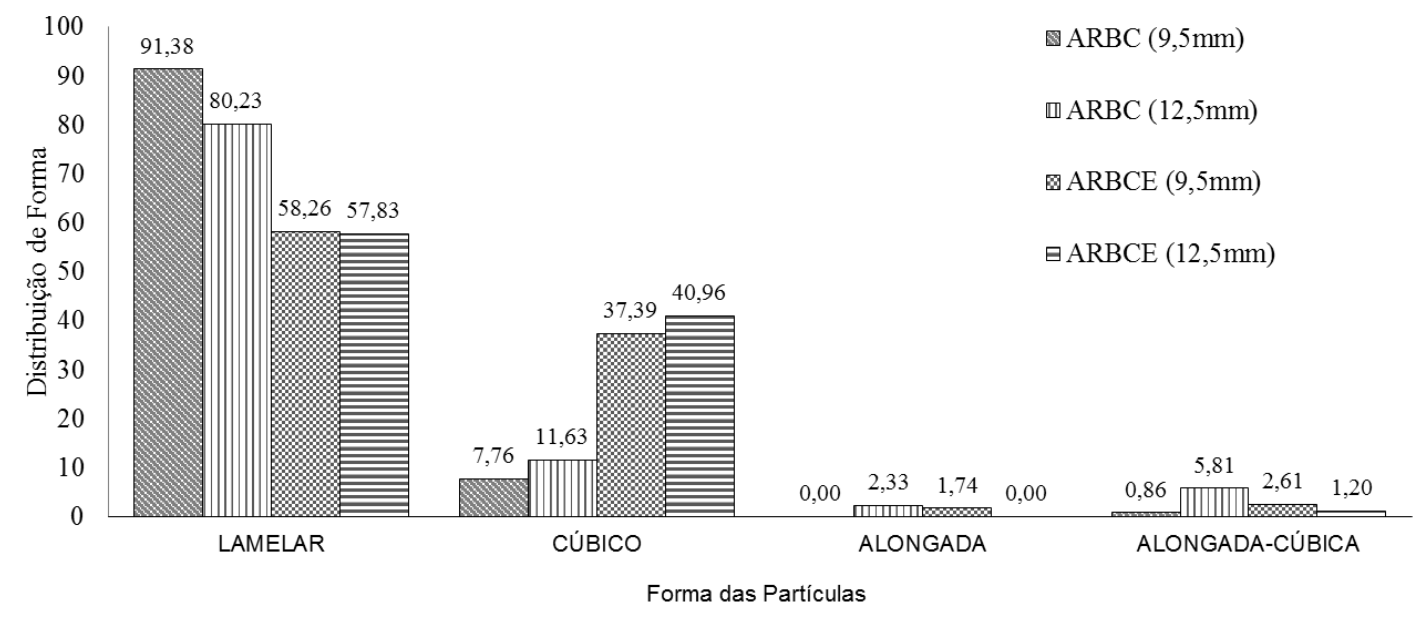

Figura 9 - Distribuição de relação entre largura e comprimento dos grãos, também conhecida como relação de aspecto (b/l)

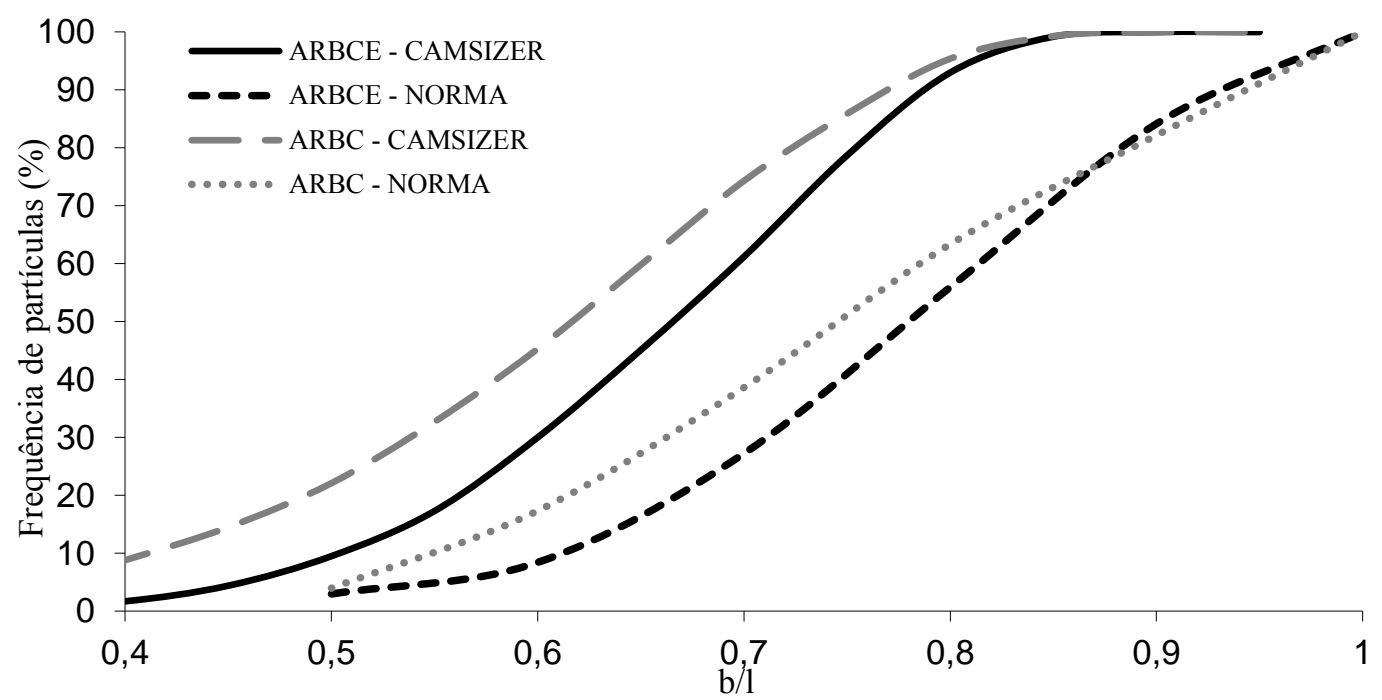

Tabela 4 - Densidade e absorção de água dos agregados reciclados

\begin{tabular}{c|c|c|c}
\hline Propriedades & ARBC & ARBCE & Métodos de ensaio \\
\hline Massa unitária $\left(\mathrm{g} / \mathrm{cm}^{3}\right)$ & 0,95 & 0,84 & NBR NM 45 (ABNT, 2006b) \\
Massa específica seca $\left(\mathrm{g} / \mathrm{cm}^{3}\right)$ & 1,96 & 1,72 & NBR NM 53 (ABNT, 2003c) \\
Absorção de água $(\%)$ & 13,05 & 11,06 & NBR NM 53 (ABNT, 2003c) \\
\hline
\end{tabular}


Figura 10 - Curvas acumuladas de absorção de água (\%) dos agregados reciclados (ARBC e ARBCE)

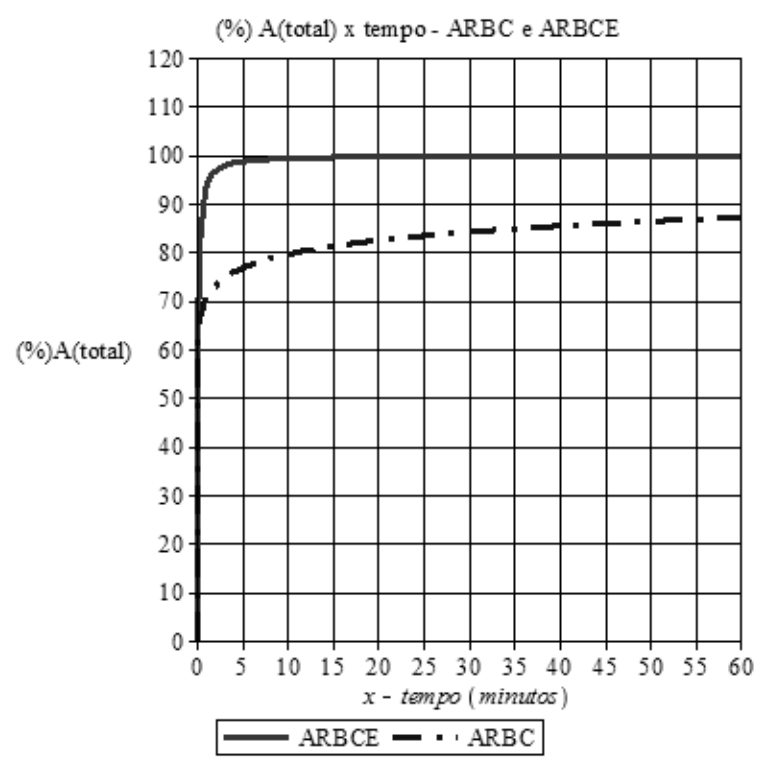

A absorção de água ocorreu de forma mais lenta para o ARBC do que para o ARBCE, fato que demonstra que o comportamento de cada agregado é diferenciado e que tanto o tempo como a porcentagem de água de absorção utilizada inicialmente devem ser determinados caso a caso. O ARBCE tem mais poros permeáveis que o $\mathrm{ARBC}$, saturando mais rapidamente.

\section{Propriedades dos concretos}

\section{Estado fresco}

$\mathrm{Na}$ Tabela 5 são apresentadas as propriedades estudadas no estado fresco para os concretos produzidos. Apesar de os concretos terem a mesma relação a/c, mesmo consumo de cimento e mesmo volume de agregados, as diferentes características dos agregados reciclados utilizados influenciaram consideravelmente na composição e nas propriedades dos concretos obtidos.

Como pode ser visto, o CARBCE apresentou maior trabalhabilidade, menor massa específica e maior teor de ar em relação ao CARBC, confirmando as características do ARBCE tais como sua melhor forma, o que pode ter melhorado a trabalhabilidade, e presença de partículas mais grossas, o que pode ter proporcionado mais vazios e menor massa específica no estado fresco.

Segundo Neville (1997), o teor de água das misturas é o principal fator que influencia na trabalhabilidade, e este independe da relação a/c e do consumo de cimento para determinado tipo de agregado. Quanto menor e mais anguloso for o agregado maior será o teor de água necessário para alcançar o abatimento desejado. Quando o teor de água e outras proporções da mistura estão fixados, a trabalhabilidade depende somente da granulometria, da textura e da forma dos agregados. Portanto, estando o teor de água e outras proporções das misturas neste estudo fixadas, o que pode justificar esse baixo abatimento da CARBC é o fato de o agregado proveniente de alvenaria cerâmica apresentar partículas mais lamelares, angulosas e irregulares.

Os valores de massa específica obtidos nos concretos foram menores que $2,00 \mathrm{~g} / \mathrm{cm}^{3}$, valor máximo da massa específica para concreto leve. Como era esperado, o CARBC apresentou massa específica mais elevada em comparação ao CARBCE, devido à utilização de agregado graúdo com maior densidade. O concreto com ARBC apresentou massa específica no limite da faixa de valores que o caracteriza como leve, mesmo sendo produzido com agregado reciclado cuja massa unitária está acima do limite máximo para agregados leves considerado na NBR NM 35 (ABNT, 1995).

Neville (1997) também relata que, quanto maior a quantidade de ar aprisionado, menor é a resistência ao adensamento. O CARBCE possui valores de teor de ar incorporado mais elevados que o CARBC e assim apresentou maior facilidade em seu adensamento. De acordo com Leite (2001), os concretos com agregados reciclados aprisionam teores significativos de ar nas misturas devido à alta porosidade que as partículas dos agregados reciclados apresentam. Além disso, o tipo do agregado reciclado utilizado também pode influenciar nesses valores. 
Levy (1997 ${ }^{1}$ apud LEITE, 2001) afirma que a redução de massa específica de concretos com agregados reciclados, devido ao total de ar incorporado, varia de $5 \%$ a $10 \%$. Portanto, a porosidade e as baixas massas específicas dos agregados graúdos reciclados utilizados, entre outros fatores, levaram à produção dos concretos com uma massa específica no estado fresco dentro do limite esperado para concreto leve.

\section{Estado endurecido}

A seguir são apresentados os resultados dos ensaios realizados no concreto no estado endurecido (Tabela 6). Como pode ser observado, a mistura ARBC apresentou valores de massa específica e de resistência à compressão maiores que os da mistura com ARBCE.

As misturas apresentaram massa específica em seu estado endurecido abaixo de $2,00 \mathrm{~g} / \mathrm{cm}^{3}$, o que, segundo a NBR 12655 (ABNT, 2006a), caracteriza um concreto leve. Como em estudos anteriores (LEITE, 2001; CARRIJO, 2005; FONSECA, 2006; NUNES, 2007), as massas específicas encontradas no estado endurecido para os concretos produzidos com agregados reciclados foram menores se comparadas às massas específicas de concretos convencionais.

Na Tabela 7 estão apresentados os resultados de massa específica e resistência à compressão de dois concretos leves da literatura que utilizaram argila expandida como agregado leve. O "A I" se refere a um concreto produzido no estudo de Maycá, Cremonini e Recena (2008), que usaram duas granulometrias de argila expandida (argilas 2215 e 1506); e o “A II" representa um concreto produzido no trabalho de Machado Júnior e Agnesini (1999). Comparando as massas específicas dos concretos "A I" e "A II" com as das misturas CARBC e CARBCE verifica-se que não há grande diferença entre os valores. Considerando-se, no entanto, a resistência à compressão axial, os concretos feitos com argila expandida apresentaram valores mais elevados, o que já era esperado, pois os concretos preparados com agregados de argila expandida têm maior resistência do que com qualquer outro agregado leve, sendo inclusive utilizados para concreto leve com função estrutural.

Ao analisar a massa específica do concreto no estado fresco e em seu estado endurecido para o CARBC e CARBCE, nota-se uma redução respectivamente de $6,60 \%$ e de $9,95 \%$, resultado também já confirmado em estudos realizados por Rossignolo (2003) e Buttler (2003), nos quais tal fato mostra a elevada perda de água que os concretos produzidos sofreram após o término do processo de cura, o que corrobora a ideia de que concretos produzidos com agregados leves apresentam maior retração do que concretos convencionais (MEHTA; MONTEIRO, 2008).

Em observação aos resultados obtidos referentes à resistência à compressão (Tabela 6) é verificado que o concreto produzido com agregados reciclados de massa específica mais baixa (agregado reciclado de blocos de concreto com EPS em sua composição) apresentou resistência inferior, o que aprova a ideia de Carrijo (2005), em cujos estudos a resistência à compressão dos concretos reciclados produzidos se reduz à medida que a massa específica dos agregados diminui. Além disso, os concretos produzidos com RCD de baixa densidade (inferior a 2,20 $\mathrm{g} / \mathrm{cm}^{3}$ ) apresentam menor resistência, tornando o concreto menos eficiente para aplicações estruturais. Na Figura 11 são mostrados os corpos de prova após serem rompidos, em que é possível perceber que houve a ruptura dos agregados reciclados (e não apenas o descolamento dos agregados e a ruptura da pasta), comprovando que os agregados apresentam resistência baixa e, provavelmente, inferior à resistência da argamassa/pasta. Segundo Etxeberria et al. (2007), para concreto convencional a interface agregado/pasta é o ponto mais fraco, no entanto este não é o caso quando o concreto é feito com agregado reciclado.

Tabela 5 - Propriedades dos concretos no estado fresco

\begin{tabular}{cccc}
\hline Propriedade & CARBC & CARBCE & Método de ensaio \\
\hline Abatimento $(\mathbf{m m})$ & 30 & 100 & NBR NM 67 (1998) \\
Massa específica $\left(\mathbf{g} / \mathbf{c m}^{3}\right)$ & 1,97 & 1,81 & NBR $9833(2008 \mathrm{~b})$ \\
Teor de $\mathbf{a r}\left(\% \mathbf{d m}^{3} / \mathbf{d m}^{3}\right)$ & 5,01 & 8,49 & NBR $9833(2008 \mathrm{~b})$ \\
\hline
\end{tabular}

${ }^{1}$ LEVY, S. M. Reciclagem do Etulho de Construção Civil, Para Utilização Como Agregado de Argamassas e Concretos. São Paulo, 1997. 147 f. Dissertação (Mestrado em Engenharia Civil) - Escola Politécnica, Universidade de São Paulo, São Paulo, 1997. 
Tabela 6 - Propriedades dos concretos no estado endurecido

\begin{tabular}{cccc}
\hline Propriedade & Mistura ARBC & Mistura ARBCE & Método de ensaio \\
\hline Massa específica $\left(\mathbf{g} / \mathbf{c m}^{\mathbf{3}}\right)$ & $1,84 \pm 0,03^{*}$ & $1,63 \pm 0,01^{*}$ & $\frac{\text { Massa Seca }}{\text { Volume Total }}$ \\
Resistência à compressão $(\mathbf{M p a})$ & $13,7 \pm 2,4^{*}$ & $9 \pm 0,4^{*}$ & NBR 5739 (2007) \\
\hline
\end{tabular}

Nota: *refere-se à média e desvio padrão.

Tabela 7 - Propriedades dos concretos produzidos com argila expandida no estado endurecido

\begin{tabular}{cccccc}
\hline Dosagem & Traço & Relação a/c & $\begin{array}{c}\text { Consumo de } \\
\text { cimento }(\mathbf{k g})\end{array}$ & $\begin{array}{c}\text { Massa específica } \\
\left(\mathbf{g} / \mathbf{c m}^{3}\right)\end{array}$ & $\begin{array}{c}\text { Resistência à } \\
\text { compressão (MPa) }\end{array}$ \\
\hline A I & $1: 3: 1,2$ & 0,65 & 250 & 1,7 & 32,0 \\
A II & $1: 1,87: 1,8$ & 0,70 & 320 & 1,54 & 20,9 \\
\hline
\end{tabular}

Figura 11 - Visualização do concreto produzido com agregado reciclado após a ruptura: A) CARBC, B) CARBCE

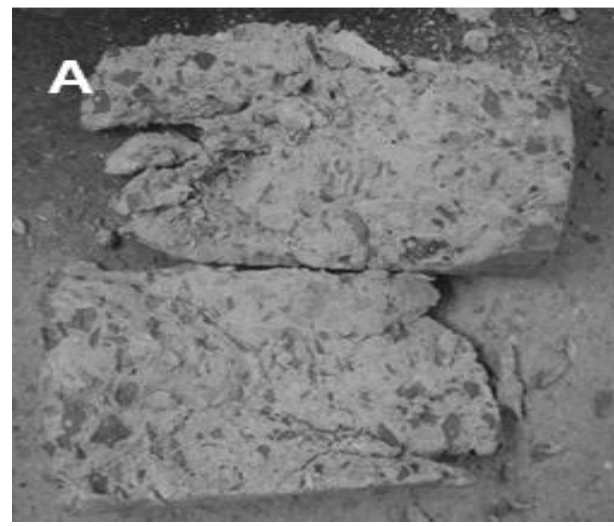

Como pode ser visto, ambos os concretos CARBC e CARBCE apresentaram resistências inferiores ao limite especificado pela NBR NM 35 (ABNT, 1995) para concretos leves estruturais, podendo ser classificados então como concretos leves isolantes ou de resistência moderada. No entanto, segundo Etxeberria et al. (2007), concreto feito com $100 \%$ de agregado graúdo reciclado pode atingir elevada resistência à compressão desde que grande quantidade de cimento seja adicionada, o que consequentemente não é uma proposta econômica. Ainda conforme o autor, concreto feito com 50\% ou $100 \%$ dos agregados grossos reciclados necessita de uma redução de $4 \%$ a $10 \%$ da relação a/c e de $5 \%$ a $10 \%$ mais cimento do que o concreto convencional para obter-se a mesma resistência à compressão aos 28 dias de um concreto convencional. Para os concretos leves produzidos, as possíveis aplicações são elementos não estruturais pré-fabricados (tais como painéis e blocos de vedação), execução de pavimentos, enchimento de lajes, entre outros. A utilização de

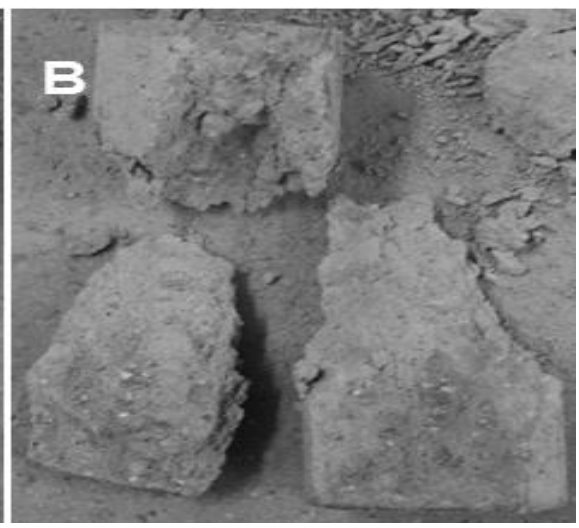

um concreto leve na produção de elementos préfabricados pode ser considerada vantajosa se forem levados em consideração os menores custos de mão de obra para manuseio, de transporte e de montagem das peças.

\section{Conclusões}

O uso de diferentes processos de cominuição produz diferentes características nos agregados reciclados. $\mathrm{O}$ processo de moinho por esmagamento (que promove o atrito entre os grãos) gerou uma granulometria com mais finos que o de britagem por impacto.

A natureza do resíduo, assim como o processo, influencia nas características dos agregados reciclados. A forma lamelar do resíduo de bloco cerâmico permaneceu no ARBC após o processo de esmagamento, indicando que a natureza do material influenciou na determinação desse parâmetro. Técnicas avançadas por imagem dinâmica, restringida à caracterização

42 Gomes, P. C. C.; Alencar, T. F. F. de; Silva, N. V. da; Moraes, K. A. de M.; Angulo, S. C. 
bidimensional da forma do agregado, comprovam que os valores determinados pela norma são superestimados e que a forma dos agregados reciclados é bem mais irregular.

Quanto à absorção, o agregado reciclado de bloco cerâmico (ARBC) apresentou maior absorção de água que o agregado reciclado de bloco de concreto contendo EPS (ARBCE), apesar do menor teor de ar. O ARBCE foi mais leve, o que indica a presença significativa de poros fechados (não permeáveis à água) neste material.

A dosagem dos concretos leves com ARBCE e ARBC para alcançar uma consistência plástica adequada limitou o diâmetro das partículas em até $19 \mathrm{~mm}$ e aumentou o teor de argamassa, confirmando alguns estudos (GIACOMIN, 2005; ROSSIGNOLO, 2003; GONZÁLEZ; SANTOS, 2012).

As características do ARBCE, melhor forma, menor massa específica e presença de partículas mais grossas, proporcionaram um concreto leve (CARBCE) com melhor trabalhabilidade, menor massa específica e maior teor de ar respectivamente em relação ao CARBC. A presença de partículas lamelares e alongadas no ARBC dificultou a ação da pasta de envolver o agregado na mistura, mesmo elevando-se o teor de argamassa seca do concreto, o que reduziu sua trabalhabilidade.

A utilização de agregados graúdos reciclados provenientes de resíduos de alvenaria cerâmica e de blocos de concreto com EPS em sua composição permitiu a produção de concretos com massa específica abaixo de $2,0 \mathrm{~g} / \mathrm{cm}^{3}$, caracterizando-os como concretos leves.

Os resultados de resistência à compressão mostraram que os concretos leves produzidos com os agregados reciclados porosos apresentaram resistências relativamente baixas, inferiores às dos concretos produzidos com agregados de argila expandida (artificiais).

A ruptura dos corpos de prova se deu pelos agregados reciclados, comprovando a baixa resistência deles, sendo inferior à resistência da argamassa/pasta, porém foi possível observar a boa aderência com a argamassa/pasta.

Agregados reciclados porosos podem ser, portanto, classificados como leves; porém são menos resistentes, devendo restringir-se ao uso em concretos sem função estrutural ou isolantes, não aumentando demasiadamente o consumo de cimento e reduzindo, conforme esperado, os impactos ambientais do concreto.

\section{Referências}

ANGULO, S. C. Variabilidade de Agregados

Graúdos de Resíduos de Construção e

Demolição Reciclados. São Paulo, 2000.

Dissertação (Mestrado em Engenharia Civil) Escola Politécnica, Universidade de São Paulo, São Paulo, 2000.

\section{ASSOCIAÇÃO BRASILEIRA DE NORMAS}

TÉCNICAS. NBR NM 35: agregados leves para concreto estrutural: especificação. Rio de Janeiro, 1995.

\section{ASSOCIAÇÃO BRASILEIRA DE NORMAS \\ TÉCNICAS. NBR NM 67: concreto:}

determinação da consistência pelo abatimento do tronco de cone. Rio de Janeiro, 1998.

\section{ASSOCIAÇÃO BRASILEIRA DE NORMAS}

TÉCNICAS. NBR 5738: concreto: procedimento para moldagem e cura de corpos-de-prova. Rio de Janeiro, 2003b.

\section{ASSOCIAÇÃO BRASILEIRA DE NORMAS TÉCNICAS. NBR NM 248: agregados:} determinação da composição granulométrica. Rio de Janeiro, 2003a.

\section{ASSOCIAÇÃO BRASILEIRA DE NORMAS} TÉCNICAS. NBR NM 53: agregado graúdo: determinação da massa específica, massa específica aparente e absorção de água. Rio de Janeiro, 2003c.

\section{ASSOCIAÇÃO BRASILEIRA DE NORMAS}

TÉCNICAS. NBR 15116: agregados reciclados de resíduos sólidos da construção civil: utilização em pavimentação e preparo de concreto sem função estrutural: requisitos. Rio de Janeiro, 2004.

\section{ASSOCIAÇÃO BRASILEIRA DE NORMAS} TÉCNICAS. NBR NM 45: agregados: determinação da massa unitária e do volume de vazios. Rio de Janeiro, 2006b.

\section{ASSOCIAÇÃO BRASILEIRA DE NORMAS}

TÉCNICAS. NBR 12655: concreto de cimento Portland: preparo, controle e recebimento: procedimento. Rio de Janeiro, 2006a.

\section{ASSOCIAÇÃO BRASILEIRA DE NORMAS}

TÉCNICAS. NBR 5739: concreto: ensaio de compressão de corpos-de-prova cilíndricos. Rio de Janeiro, 2007.

\section{ASSOCIAÇÃO BRASILEIRA DE NORMAS \\ TÉCNICAS. NBR 9833: concreto fresco:}

determinação da massa específica e do teor de ar pelo método gravimétrico. Rio de Janeiro, 2008b. 
ASSOCIAÇÃO BRASILEIRA DE NORMAS TÉCNICAS. NBR 7809: agregado graúdo? determinação do índice de forma pelo método do paquímetro: método de ensaio. Rio de Janeiro, 2008a.

ASSOCIAÇÃO BRASILEIRA DE NORMAS TÉCNICAS. NBR 7211: agregados para concreto: especificação. Rio de Janeiro, 2009.

ASSOCIAÇÃO BRASILEIRA DE NORMAS TÉCNICAS. NBR 5564: via férrea: lastro ferroviário: requisitos e métodos de ensaio. Rio de Janeiro, 2011.

ASSOCIAÇÃO BRASILEIRA DE NORMAS TÉCNICAS. NBR 11578: cimento Portland composto. Rio de Janeiro, 1991.

BUTTLER, A. M. Concreto Com Agregados Graúdos Reciclados de Concreto: influência da idade de reciclagem nas propriedades dos agregados e concretos reciclados. São Paulo, 2003. Dissertação (Mestrado em Engenharia Civil) Escola de engenharia, Universidade de São Paulo, São Paulo, 2003.

CARRIJO, P. M. Análise da Influência da Massa Específica de Agregados Graúdos Provenientes de Resíduos de Construção e Demolição no Desempenho Mecânico do Concreto. São Paulo, 2005. Dissertação (Mestrado em Engenharia Civil) - Escola Politécnica, Universidade de São Paulo, São Paulo, 2005.

ETXEBERRIA, M. et al. Influence of Amount of Recycled Coarse Aggregates and Production Process on Properties of Recycled Aggregate Concrete. Cement and Concrete Research, v. 37, n. 5, p. 735-742, 2007.

FARIAS, M. M.; PALMEIRA, E. M. Agregados

Para a Construção Civil. In: ISAIA, G. C.

Materiais de Construção Civil e Princípios de

Ciência e Engenharia de Materiais. São Paulo: Ibracon, 2010.

FERREIRA, L.; BRITO, J. de; BARRA, M. Influence of the Pre-Saturation of Recycled Coarse Concrete Aggregates on Concrete Properties. Magazine of Concrete Research, v. 63, n. 8, p. 617-627, 2011.

FONSECA, A. P. Estudo Comparativo de Concretos Com Agregado Graúdo Reciclado de Telha Cerâmica e Agregado Graúdo Natural. Uberlândia, 2006. Dissertação (Mestrado em Engenharia Civil) - Escola de Engenharia, Universidade Federal de Uberlândia. Uberlândia, 2006.
GANESH BABU, K.; SARADHI BABU, D. Behaviour of Lightweight Expanded Polystyrene Concrete Containing Sílica Fume. Cement and Concrete Research, v. 2249, p. 1-8, 2002.

GIACOMIN, R. C. Estudo das Propriedades do Concreto Com Argila Expandida. 35 f. Porto Alegre, 2005. Trabalho de Conclusão de Curso (Curso de Engenharia Civil) - Pontifícia Universidade Católica do Rio Grande do Sul, Porto Alegre, 2005.

GOMES, P. C. C. et al. Obtenção de Argamassas Com Agregados Reciclados Produzidos na Obra Para Uso em Revestimento. In: ENCONTRO NACIONAL DE TECNOLOGIAS DO AMBIENTE CONSTRUÍDO, 13., Canela, 2010. Anais... Canela: ANTAC, 2010.

GOMES, P. C. C. et al. Comparação de Propriedades de Argamassas Com Resíduos Produzidas no Laboratório e na Obra. In: SIMPÓSIO BRASILEIRO DE TECNOLOGIA DE ARGAMASSAS, Belo Horizonte, 2011. Anais... Belo Horizonte, 2011.

GONZÁLEZ, M. L.; SANTOS, S. D. A Utilização de Flocos de EPS na Fabricação de Concreto Leve: uma solução ambientalmente sustentável. In: SIMPÓSIO INTERNACIONAL SOBRE CONCRETOS ESPECIAIS, 5., Fortaleza, 2012. Anais... Fortaleza, 2012.

HAWLITSCHECK, G. et al. Análise de Imagens Por Fluxo Dinâmico de Partículas. Brasil Mineral, v. 329, p. 82-85, 2013.

LAUKAITIS, A.; ZURAUSKAS, R.; KERIEN, J. The Effect of Foam Polystyrene Granules on Cement Composite Properties. Cement \& Concrete Composites, v. 27, p. 41-47, 2003.

LEITE, M. B. Avaliação de Propriedades Mecânicas de Concretos Produzidos Com Agregados Reciclados de Resíduos de Construção e Demolição. Porto Alegre, 2001.

Tese (Doutorado em Engenharia Civil) - Programa de Pós-Graduação em Engenharia Civil, Universidade Federal do Rio Grande do Sul, Porto Alegre, 2001.

LO, Y.; GAO, X. F.; JEARY, A. P.

Microstructure of Pre-Wetted Aggregate on Lightweight Concrete. Department of Building and Construction, City University of Hong Kong. Hong Kong, 1998. 
MACHADO JUNIOR, E. F.; AGNESINI, M. V.

C. Estudo Comparativo das Propriedades Físicas e Mecânicas de Microconcretos Leves Produzidos Com Argila Expandida e Com Agregados Reciclados de Rejeitos de Construção e Demolição. In: CONGRESSO BRASILEIRO DO CONCRETO, 41., Salvador, 1999. Anais... Salvador, 1999.

MAYCÁ, J.; CREMONINI, R. A.; RECENA, F. A. Contribuição ao Estudo da Argila Expandida Nacional Como Alternativa de Agregado Graúdo Para Concretos Leves Estruturais (CLE). Trabalho apresentado no Curso de Especialização em Construção Civil 2006/2008 - NORIE, Universidade Federal do Rio Grande do Sul, Porto Alegre, 2008.

MEHTA, P. K.; MONTEIRO, P. J. M. Concreto: microestrutura, propriedades e materiais. 3. ed. São Paulo: Ibracon, 2008.

MILED, K. et al. Compressive Behavior of an Idealized EPS Lightweight Concrete: size effects and failure mode. Mechanics of Materials, v. 36, n. 11, p. 1031-1046, 2004.

MORAVIA, W. G. et al. Caracterização Microestrutural da Argila Expandida Para Aplicação Como Agregado em Concreto Estrutural Leve. Cerâmica, v. 52, p. 193-199, 2006.

NEVILle, A. M. Propriedades do Concreto. 2. ed. São Paulo: Pini, 1997.

NUNES, W. C. Influência do Agregado Graúdo Reciclado de Resíduos da Construção Predial nas Propriedades do Concreto Fresco e Endurecido. Goiânia, 2007. Dissertação (Mestrado em Engenharia Civil) - Escola de Engenharia Civil, Universidade Federal de Goiás, Goiânia, 2007.

OLIVEIRA, M. B. de; VAZQUEZ, E. The Influence of Retained Moisture in Aggregates from Recycling on the Properties of New Hardened Concrete. Waste Mangement, v. 16, n. 1-3, p. 113-117, 1996.

POON, C. S. et al. Influence of Moisture States of Natural and Recycled Aggregates on the Slump and Compressive Strength of Concrete. Cement and Concrete Research, v. 34, n. 1, p. 31-36, 2004.
RODRIGUES, C. R. S. Avaliação de Propriedades Mecânicas de Concretos Produzidos Com Agregado Miúdo Reciclado de Resíduo da Construção Civil. Recife, 2011. 118 f. Dissertação (Mestrado em Engenharia Civil) Escola Politécnica, Universidade de Pernambuco, Recife, 2011.

ROSSIGNOLO, J. A. Concreto Leve de Alto Desempenho Modificado Com SB Para PréFabricados Esbeltos: dosagem, produção, propriedades e microestrutura. São Carlos, 2003. 211 f. Tese (Doutorado em Ciência e Engenharia de Materiais) - Escola de Engenharia, Universidade de São Paulo, São Paulo, 2003.

ROSSIGNOLO, J. A.; AGNESINI, M. V. C. Concreto Estrutural Leve. In: ISAIA, G. C. Concreto: ensino, pesquisa e realizações. São Paulo: Ibracon, 2005.

ROSSIGNOLO, J. A. Concreto Leve Estrutural: influência da argila expandida na microestrutura da zona de transição pasta/agregado. Ambiente Construído, Porto Alegre, v. 9, n. 4, p. 119-127, out./dez. 2009.

SILVA, K. A. N. Estudo de Propriedades Mecânicas de Concretos Produzidos Com Diferentes Agregados Reciclados. Dissertação (Mestrado em Engenharia Civil) - Escola de Engenharia, Universidade Federal de Alagoas, Maceió, 2011.

TENÓRIO, J. J. L. Avaliação de Propriedades do Concreto Produzido Com Agregados Reciclados de Resíduos de Construção e Demolição Visando Aplicações Estruturais. Maceió, 2007. Dissertação (Mestrado em Engenharia Civil) - Escola de Engenharia, Universidade Federal de Alagoas, Maceió, 2007.

\section{Agradecimentos}

Os autores agradecem à Capes, ao CNPq, à Finep e aos projetos Universal/2012 e PROCAD/casadinho 2011, pelo suporte financeiro proporcionado ao trabalho; às construtoras Borela e Cerutti e ao Laboratório de Estruturas e Materiais (LEMA) da UFAL, pelo fornecimento de recursos humanos, materiais e equipamentos. 


\section{Paulo César Correia Gomes}

Laboratório de Estruturas e Materiais, Centro de Tecnologia | Universidade Federal de Alagoas | Av. Lourival Melo Mota, $\mathrm{Br} 104 \mathrm{~km} 14$, Campus A. C. Simões, Tabuleiro dos Martins | Maceió - AL - Brasil | CEP 57029-070 | Tel.: (82) 3214-1721 | E-mail: pgomes@ctec.ufal.br

Tatiana Frassy Falcão de Alencar

Companhia de Saneamento de Alagoas | Rua Barão de Atalia, 200, Centro | Maceió - AL - Brasil | CEP 57020-510 | E-mail: tatifrassy@hotmail.com

\section{Natália Vieira da Silva}

Laboratório de Estruturas e Materiais, Centro de Tecnologia | Universidade Federal de Alagoas | E-mail: nataliavieira.tec.edif@gmail.com

\section{Karoline Alves de Melo Moraes}

Laboratório de Estruturas e Materiais, Centro de Tecnologia | Universidade Federal de Alagoas | Tel.: (82) 3214-1733 | E-mail: melokarol@gmail.com

\section{Sérgio Cirelli Angulo}

Escola Politécnica | Universidade de São Paulo | Rua Professor Almeida Prado, 532, Prédio 01, Cidade Universitária, Butantã | São Paulo SP - Brasil | CEP 05508-900 | Tel.: (11) 3091-5793 | E-mail: sergio.angulo@lme.pcc.usp.br

\section{Revista Ambiente Construído}

Associação Nacional de Tecnologia do Ambiente Construído

Av. Osvaldo Aranha, $99-3^{\circ}$ andar, Centro

Porto Alegre - RS - Brasil

CEP $90035-190$

Telefone: +55 (51) 3308-4084

Fax: +55 (51) 3308-4054

www.seer.ufrgs.br/ambienteconstruido

E-mail: ambienteconstruido@ufrgs.br

46 Gomes, P. C. C.; Alencar, T. F. F. de; Silva, N. V. da; Moraes, K. A. de M.; Angulo, S. C. 